\title{
O que não é sólido desmancha no ar
}

Às palavras-chave em relações públicas, imagem e reputação pode-se associar a ideia de que "vale quanto se percebe", mas a cada dia e cada vez mais isso não é tudo em que se deva crer. Festejada por muitas pessoas e organizações nos últimos anos, a sustentabilidade tem em sua história a crescente importância que lhe é dada por mídia, autoridades, organizações, órgãos de certificações, sociedade civil, lideranças e, sobretudo, opinião pública. E é exatamente por isso que se deve tratá-la no âmbito da forma e do conteúdo. Existem gradações, escalas, dimensões para cada olhar sobre a sustentabilidade.

Pautada recorrentemente pelos meios de comunicação, a sustentabilidade hoje ocupa a agenda de discussão quando o tema é presente e especialmente futuro. Seja pelo aspecto humano e/ou a preocupação com o porvir, seja pelas questões ambientais e seus desdobramentos, seja pelo equilíbrio necessário à economia e a sua imbricação com os outros dois elementos, o fato é que esse assunto está na agendas da contemporaneidade. Desde quando se publicou o Relatório Brundtland, consubstanciado no livro Our common future (1987) e passando pela Conferência da Organização das Nações Unidas Sobre o Desenvolvimento Sustentável, a Rio+20, que teve como temas principais o desenvolvimento de uma economia verde para o desenvolvimento sustentável e eliminação da pobreza; e a definição da governança global da sustentabilidade. 
$\mathbf{T}$ odas as questões que envolvem a sustentabilidade ganharam força e passaram a constituir pesquisas e práticas, geraram ações concretas em todas as esferas. A sociedade civil organizada demanda posicionamentos claros por parte das áreas pública, privada e do terceiro setor. Essa valoração deve-se a um par de fatos, que deve ser destacado como essencial para o que hoje se entende e se faz em relação à temática da sustentabilidade

A partir desses fatos motores, diversos outros acontecimentos reforçaram o assunto que teve seus primeiros passos na década de 1980. Afinal, os grandes movimentos culturais - impactando religiões, economia, política - não são apartados das demandas percebidas ou até são aparentemente imperceptíveis pelos cidadãos. Para o cientista Lester Brown, o que ele chama de "revolução ambienta" precisa, para ser bem-sucedida, ter na economia global novos rumos de desenvolvimento que levem em conta a sustentabilidade ambiental sustentável, o que oferecerá maior segurança à economia, fomentará estilos de vida mais saudáveis e propiciará melhores condições humanas em nível mundial.

$\mathrm{Na}$ contemporaneidade, as empresas são chamadas a se conscientizarem de que precisam abandonar a mentalidade voltada tão-somente, ou de forma predominante, para a otimização dos lucros, a fabricação de produtos e a prestação de serviços. Escreve Leonardo Boff, a propósito, em Ecologia: grito da terra, grito dos pobres (2004): "Há quatro séculos todas as sociedades mundiais são reféns de um mito: o mito do progresso e do crescimento ininterrupto e ilimitado. Cada ano todo país deve ostentar taxas crescentes na produção de bens e serviços".

Vargas Llosa, em sua obra A civilização do espetáculo (2012), destaca que cultura é também um estilo de vida, uma maneira de ser em que as formas têm tanta importância quanto o conteúdo. Ou mesmo a indissociação de ambas. As transformações contemporâneas levam a novas necessidades e estas, a novas maneiras de enxergar o que antes seria concreto e agora se dilui, se liquidifica, perdendo o conceito de solidez que de algum modo basearia a reputação.

A configuração de uma sociedade global e de novos organismos supranacionais altera as relações internacionais e desempenha uma função ativa e desterritorializada, ditando regras e ajustes aos estados nacionais. Nesse contexto são exigidas novas formas de comunicação, movidas pelas tecnologias que impulsionam e permitem operacionalizar as grandes redes de computadores e todo o instrumental tecnológico da era digital. Assim, os sistemas mundiais de comunicação são hoje formados por redes, permitindo que todas as sociedades estejam conectadas simultaneamente, de forma única e em tempo real, graças aos processos de globalização e modernização da mídia, dentro do que Anhony Giddens chama de globalização da modernidade.

Em tempos de tempo real, no qual as tecnologias fomentam um empoderamento da opinião pública, a percepção de espaço e tempo se reconfiguram, se ressignificam e geram também novos processos culturais. O discurso sobre sustentabilidade passa a ser acompanhado em novas 
redes, atentas, bem informadas, interessadas, que podem influir nas opiniões de seus pares e reverberar blocos de inspiração, levando a verdadeiros movimentos pró ou contra ações, ideias, organizações ou até pessoas. Por isso, é necessário que o discurso seja sólido, concreto. Senão, se desmanchará no ar, cada dia mais volátil.

À comunicação cabe a ação efetiva de gerir relacionamentos, de fazer palavras e ações se tornarem mais significativas, correspondentes ao real. Quando a comissão editorial de Organicom se decidiu pelo tema "sustentabilidade e comunicação" para ancorar o dossiê desta edição, já sabia do grande interesse e da importância que esse assunto gera nos nossos dias. Talvez não se tivesse a plena ideia de com que volume e com que dimensão qualitativa seria a produção a ser apresentada. Recebemos muitos e valiosos artigos. Foi longa e proveitosa a atividade de avaliação dos textos pelo conselho editorial desta publicação.

Organicom chega a seu $18^{\circ}$ número trazendo o dossiê "Comunicação e sustentabilidade!" com a certeza de que os temas em comunicação organizacional e relações públicas dia a dia se ampliam e se tornam mais sonoros, a ouvidos especializados e mesmo aos leigos que, mesmo sem saber, se servem delas. As duas áreas ganham adeptos e pesquisadores. Cada dossiê tem se erguido à estatura de uma obra de referência, de material a ser cuidadosamente estudado e adequado a servir de base para pestudiosos e profissionais. Aliás, tem sido uma característica da revista a sintonia entre o pensar e o fazer, que não podem se dissociar.

Este número traz como conteúdo um conjunto de dezenove trabalhos - dois na seção "Espaço aberto", dez no "Dossiê", quatro em "Pesquisa" e três em "Resenha". Os textos foram aceitos pelo Conselho Científico-Editorial, do qual fazem parte dezenas de pesquisadores dos mais importantes centros de pesquisa brasileiros e internacionais ligados ao campo de produção da Organicom.

"Espaço aberto" conta com dois artigos. No texto "A comunicação em torno do risco: algumas considerações", Arlette Bouzon, vai além dos estudos de crise e dos problemas semânticos originais relacionados a esse termo. Trata-se de um artigo que traz à tona uma temática que já mereceu um dossiê exclusivo de Organicom, em seu número 7, e continua de absoluta atualidade e relevância. Tendo estudado em sua pesquisa de mestrado a temática das narrativas relacionadas às organizações, Rodrigo Silveira Cogo produziu o texto "Em busca de novas narrativas organizacionais: análise de conteúdo audiovisual e proposta de matriz estruturante em storytelling", em que utiliza a técnica de análise de conteúdo.

O "Dossiê", por sua vez, remete ao tema central deste número: "Comunicação e sustentabilidade". A partir dele pode-se perceber a massa crítica de cientistas brasileiros já existente em torno desse assunto. Os professores Colleen M. Scanlan Lyons e Stanley Deetz, ambos da Universidade do Colorado (EUA), exploram a interação entre processos de responsabilidade social e integração com as temáticas comunitárias, levando à conscientização comunitária. 
Rudimar Baldissera e Cristine Kaufmann, no artigo "Comunicação organizacional e sustentabilidade: sobre o modelo instituído no âmbito da organização comunicada", utilizam a pesquisa exploratória para discutir o processo enunciativo organizacional, centrado, segundo se conclui, no aspecto econômico.

Márcio Simeone Henriques e Lidiane Ferreira Sant'Ana apresentam o artigo "Ideias-força evidenciadas no discurso organizacional sobre sustentabilidade", no qual exploram o conceito-título de ideia-força de que se valem as organizações para equilibrar as pressões sociais e legais por responsabilidade ambiental.

Já as autoras Fabiane da Silva Verissimo, Fernanda Sagrilo Andres, Marcela Guimarães e Silva e Maria Lília Dias de Castro, em seu texto "A sustentabilidade na perspectiva comunicacional e discursiva", recorrem à campanha publicitária da Eletrobras em 2011 para analisar estratégias discursivas e comunicativas.

Daniela Viegas e Armindo dos Santos de Sousa Teodósio, com o artigo "Comunicação e sustentabilidade no esteio da cidadania: um estudo sobre a (des)articulação entre organizações na esfera pública", discutem as tensões presentes entre os diversos atores sociais, mesmo na presença de um discurso tido como politicamente correto, visto ser uma zona de tensões e conflitos.

As pesquisadoras Morgana Monteiro Batistella e Marlene Marchiori adotam em seu estudo o olhar sobre a comunicação nas perspectivas informacional e relacional, dando origem ao artigo "O processo comunicacional e as práticas sustentáveis nas organizações", cuja base foi um estudo empírico realizado em uma indústria de grande porte. O estudo concluiu pela relação entre a sustentabilidade e os processos comunicacionais das organizações.

Na mesma linha de vinculação a uma experiência real, Priscila Muniz de Medeiros e José Afonso da Silva Júnior produziram um estudo sobre os espaços de disputa simbólica nas redes sociais, gerando como fruto "As disputas argumentativas em torno do novo Código Florestal no Twitter: comunicação, economia e sociedade na perspectiva ambiental". Os debates naquele microblog em torno do controverso tema levou os pesquisadores a concluir parcialmente pela pluralidade do debate.

Gisele Dotto Reginato e Débora Flores Dalla Pozza utilizam a base teórica francesa da análise do discurso para avaliar, a partir de press releases da empresa Vale, a presença de fragmentos sobre o tema da responsabilidade ambiental, no artigo "O discurso da responsabilidade social e da sustentabilidade na comunicação organizacional da Vale”.

Para produzir "As várias faces da moeda: representações da responsabilidade social em um banco brasileiro, Luíza Mônica Assis da Silva, Ana Lúcia Galinkin e Angela Maria de Oliveira Almeida trabalharam a partir do método da análise semiótica Elas (utilizaram corpi de peças de 
propaganda instituicional e aplicaram pesquisa com mais de mil pessoas, dentre clientes e funcionários de uma instituição financeira brasileira de grande porte, constatando representações diversas de acordo com predisposições dos públicos.

Luciana Oliveira e Otávio Dulci colocam em xeque o conceito de responsabilidade social empresarial no Brasil, uma verdadeira bandeira assumida pelas classes empresariais, ao contrário de outros países, como no caso argentino, onde setores da sociedade civil, por exemplo, o fizeram. O estudo dos pesquisadores pode ser conhecido mais de perto no texto "Elites empresariais, a questão social e a responsabilidade social empresarial no Brasil e na Argentina".

Fruto de trabalhos em nível de stricto sensu, grupos de pesquisa ou mesmo individuais, a seção "Pesquisa" traz quatro artigos também ligados ao tema central de"Comunicação e sustentabilidade". O volume e valor dos textos vai ao encontro da demanda por produção de saber das áreas de comunicação organizacional e de relações públicas, cujos pesquisadores estão ávidos pela ampliação do debate.

O primeiro texto da seção,"O discurso da sustentabilidade: construção de sentido para a comunicação interna", é de Wilma Pereira Tinoco Vilaça, que se debruça sobre a relação direta entre a fala organizacional ligada à sustentabilidade como elemento discursivo impactante nos profissionais.

Focando no primeiro setor, o artigo "Comunicação pública como prática de responsabilidade social das organizações públicas”, de Gisele Rosso e Celsi Brönstrup Silvestrin, tendo como pano de fundo uma pesquisa realizada em órgão público do Paraná. As autoras discutem a comunicação pública como elemento fomentador da sustentabilidade quando se utiliza a transparência e a valorização da cidadania

Otávio Freire, Filipe Quevedo-Silva e Elias Frederico, em "Mensurando a consciência ambiental do consumidor: um estudo comparativo entre as escalas NEP e ECCB", trazem para o tema da sustentabilidade um elemento - assim como em muitas outras áreas, nas quais se inclui a comunicação - de grande relevância e ainda em processo de amadurecimento: a avaliação de resultados, para o que utilizaram a técnica de comparação entre duas escalas e aplicaram um estudo de campo com mais de quinhentos consumidores brasileiros.

Wellington Teixeira Lisboa e Taise Fernandes Luz apresentam o artigo "A sustentabilidade econômica como posicionamento estratégico nos negócios da "nova" Baixada Santista: demandas profissionais às relações públicas", a partir de olhar sobre uma importante região econômica e cultural do Estado de São Paulo e seu desenvolvimento, identificando os desafios colocados para as relações públicas pelo crescimento econômico.

Mantendo o perfil, Organicom trouxe para a seção de "Entrevista" um grande especialista no tema do dossiê, como vem fazendo desde a sua primeira edição. O CEO da Global Reporting 
Initiative (GRI), o holandês Ernst Ligteringen, transmitiu à pesquisadora Vivian Paes Barretto Smith sua experiência mundial à frente de uma organização muito conhecida também por brasileiros, considerando sua metodologia muito respeitada para a construção de relatórios sobre sustentabilidade com indicadores de desempenho. Na conversa entre entrevistadora e entrevistado pode-se ver a amplitude de possibilidades no uso da comunicação como elemento estratégico na gestão da sustentabilidade e na construção de um lugar de fala que dê cada vez mais importância ao tema.

Como um riquíssimo testemunho a complementar a fala de Ligteringen, a seção "Depoimentos" traz uma expressiva contribuição de Ricardo Voltolini: "12 lições aprendidas sobre comunicação da sustentabilidade em empresas: reflexões breves e propositadamente inconclusas". Nela, esse grande nome brasileiro vinculado com o estudo e à prática na área delineia orientações relativas à comunicação da sustentabilidade, baseadas em sua ampla vivência profissional.

Este número abriga ainda resenhas de três livros: Comunicação pública: bases e abrangências, de Mariangela Haswani; Marketing e gestão do esporte, de Ary Rocco; e Propaganda, identidade e discurso: brasilidades midiáticas, de Eneus Trindade. As resenhas foram escritas, respectivamente, por Patricia Salvatori, Luiz Alberto de Farias e Vânia Penafieri, brindando os leitores com a crítica sobre produções que dão conta de três focos bem específicos da comunicação.

Após quase uma década de trabalho, Organicom chega a seu $18^{\circ}$ número mantendo a preocupação de atender às demandas de uma comunidade científica cuja produção é marcada por uma qualidade cada vez mais elevada. Busca-se, também, a todo tempo, seguir o rigor dos padrões bibliométricos, facilitando o acesso, disponibilizando ao maior número de pessoas a íntegra de seu conteúdo e aumentando o rigor na seleção e na edição dos textos.

Luiz Alberto de Farias Margarida M. Krohling Kunsch 


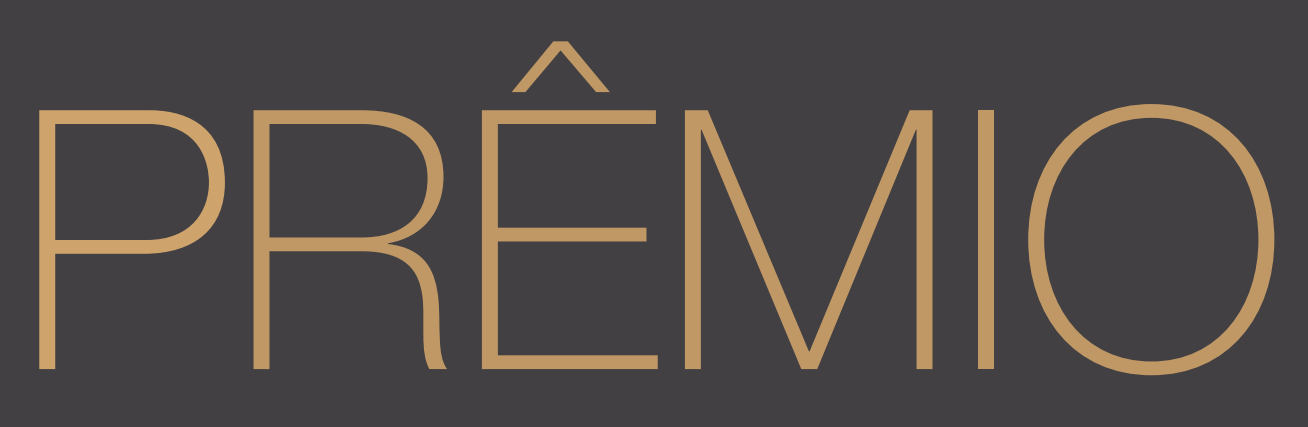

O

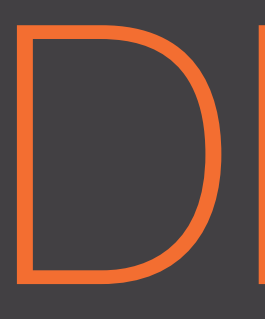
EB

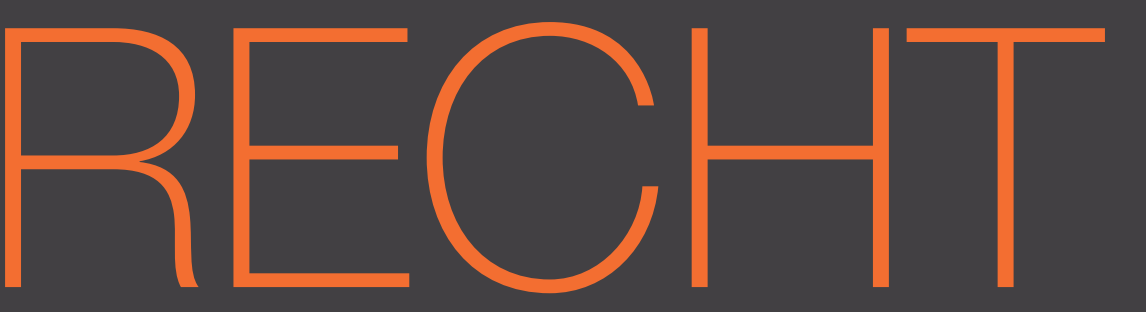

$\square$
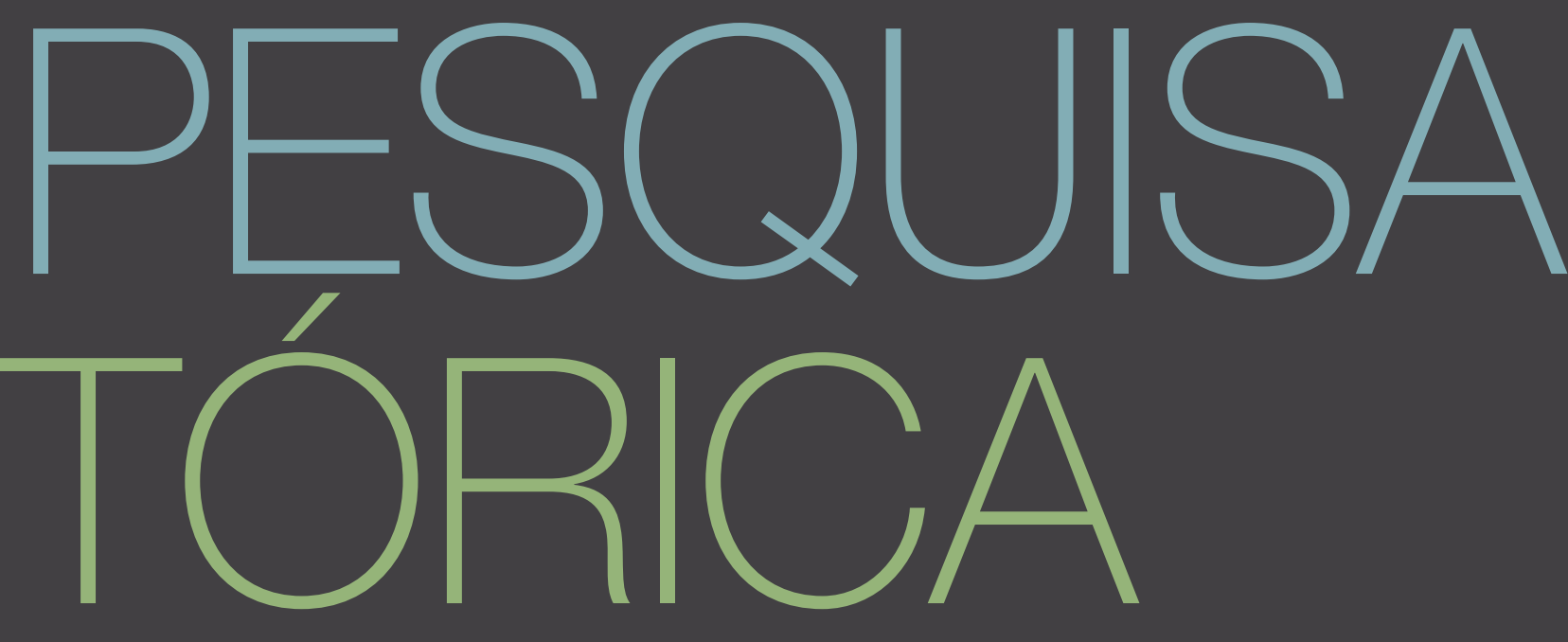

HISTORICA

CLARIVAL DO PRADO VALLADARES
CLARIVAL DO PRADO VALLADARES
HÁ 10 ANOS ESTIMULANDO A DESCOBERTA E A PRESERVAÇÃO DA MEMÓRIA BRASILEIRA

Desde 2003 o Prêmio Odebrecht de Pesquisa Histórica vem apoiando o trabalho de pesquisadores que se dedicam a temas inéditos da História do Brasil.

A cada ano, um projeto de pesquisa é financiado, e seu resultado é colocado à disposição do público em um livro de arte cuidadosamente editado e ricamente ilustrado.

Dessa forma, a Organização Odebrecht ajuda a valorizar o patrimônio cultural brasileiro e a preservar a nossa memória para as futuras gerações.

If/premioodebrechthistoria | www.odebrecht.com/pesquisahistorica
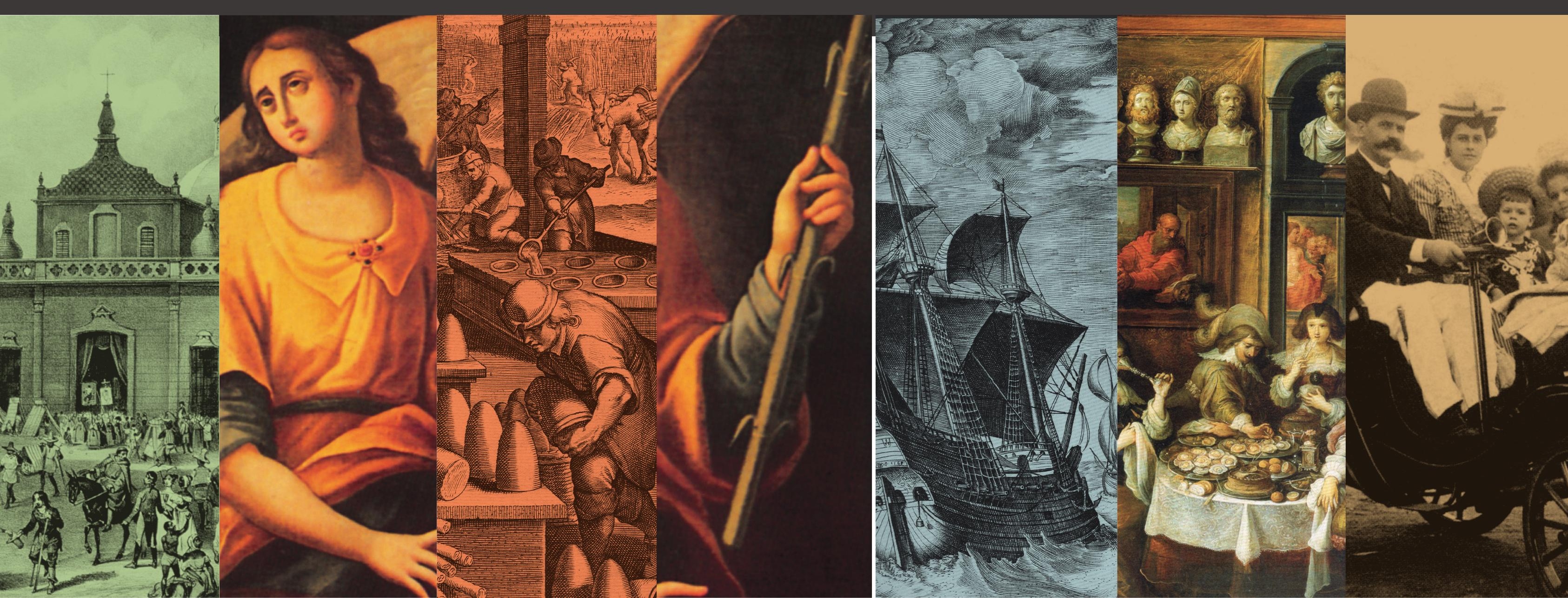

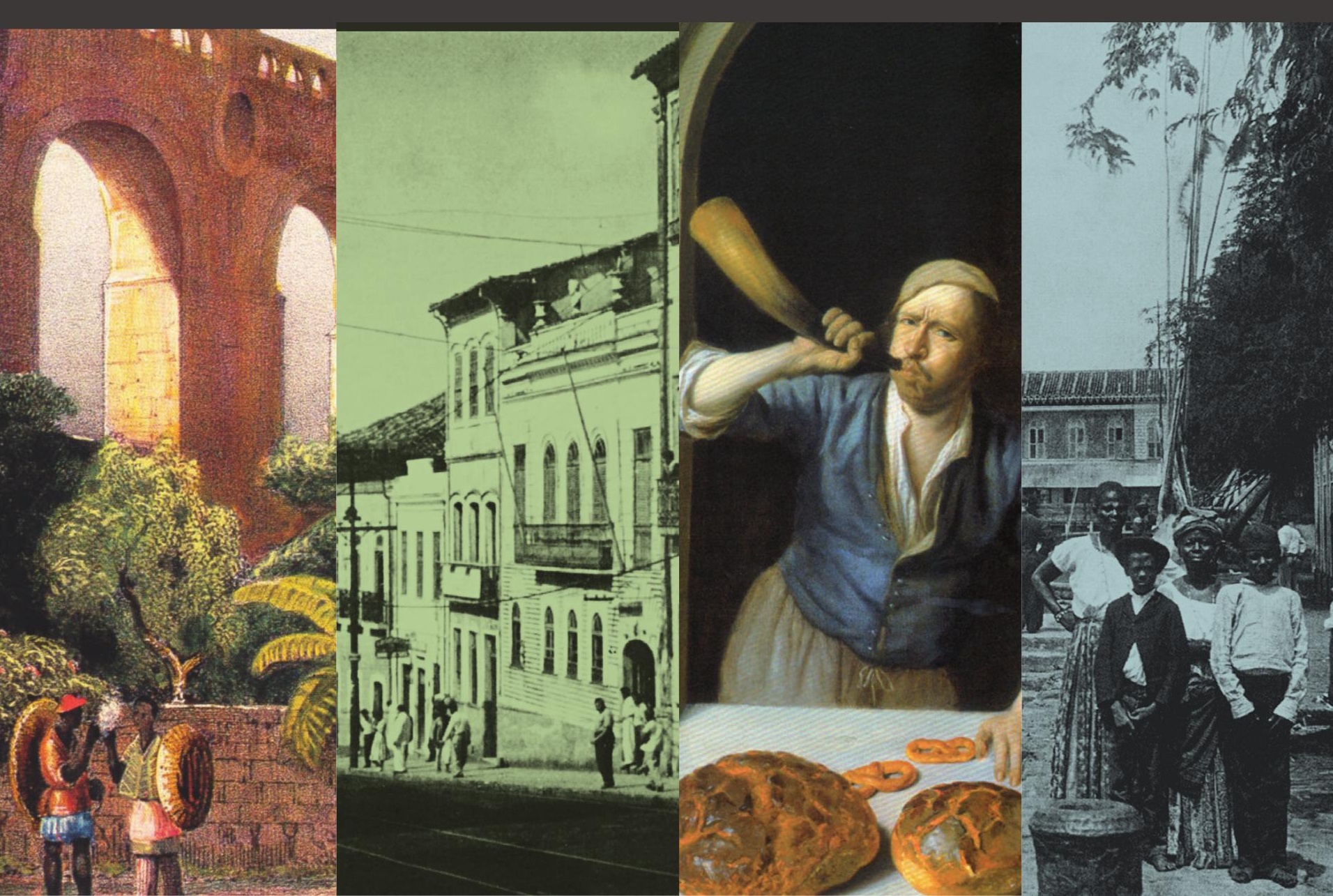

